Original Research Article

\title{
Antimicrobial utilization pattern in Systemic Inflammatory Response Syndrome positive septicemia: a prospective study in an apex hospital in South Delhi
}

\author{
Anwer Habib ${ }^{1}$, Razi Ahmad ${ }^{2 *}$
}

${ }^{1}$ Department of Medicine, ${ }^{2}$ Department of Pharmacology, HIMSR, Jamia Hamdard, New Delhi-110062, India

Received: 03 January 2019 Accepted: 29 January 2019

*Correspondence to:

Dr. Razi Ahmad, Email: rahmad50@gmail.com

Copyright: (C) the author(s), publisher and licensee Medip Academy. This is an openaccess article distributed under the terms of the Creative Commons Attribution NonCommercial License, which permits unrestricted noncommercial use, distribution, and reproduction in any medium, provided the original work is properly cited.

\begin{abstract}
Background: Despite significant advances in critical care, mortality and morbidity in severe sepsis and septic shock remain high, this may be explained by the fact that in sepsis bacterial infection triggers the innate immune response, setting in motion a cascade of pro-inflammatory and anti-inflammatory cytokines leading to what we recognize as the systemic inflammatory response syndrome (SIRS). It has been thought that this self-propagating cascade drives the progression to severe sepsis and septic shock with increasing degrees of cellular injury and end-organ dysfunction, therefor early initiation of empirical antimicrobial agent is crucial and life-saving atleast in high risk patient. This study aimed to see the outcome (recover or mortality) of patients diagnosed by using SIRS criteria.
\end{abstract}

Methods: Total of 105 patients of suspected sepsis fulfilling SIRS criteria (SIRS $\geq 2$ ), were included in study. Study population were administered appropriate empirical antimicrobial depending on the source of infection and followed till the final outcome (complete recovery or death).

Results: Out of 105 patients included in study based on SIRS criteria, 87 $(82.85 \%)$ were confirmed to be having septicemia on further evaluation. In majority of patient primary source of infection were respiratory tract $(44.76 \%)$ and most commonly employed and effective empirical antimicrobial were a combination piperacillin with tazobactum and amikacin (40\%). 92.39\% patients recovered with empirical antimicrobial, with total in-hospital mortality rate of $7.61 \%$.

Conclusions: Early initiation of appropriate antimicrobial by using SIRS as an indicator for the early diagnosis of septicemia is crucial in the management of septicemia and prevention of development of severe sepsis, septic shock.

Keywords: Antimicrobial, Septicemia, SIRS, Septic shock

\section{INTRODUCTION}

While systems-based strategies incorporating bundles to guide volume resuscitation and timely antimicrobial therapy have improved clinical outcomes for many patients, severe sepsis and septic shock still carry an unacceptably high mortality. ${ }^{1}$ Contemporary management of severe sepsis and septic shock rests solidly on its conceptualization as an immunologic disease. In this paradigm, bacterial infection triggers the innate immune response, setting in motion a cascade of pro-inflammatory and anti-inflammatory cytokines (e.g. IL-1 $\beta, \mathrm{TNF}-\alpha$ and IL-6), leading to systemic inflammatory response syndrome (SIRS). ${ }^{2}$ It has been thought that this selfpropagating cascade drives the progression to severe sepsis and septic shock with increasing degrees of cellular injury and end-organ dysfunction, irrespective of the initial infectious trigger and its rapid elimination with antimicrobial therapy. ${ }^{3}$ Clinical manifestations of this intense inflammatory response include a constellation of 
coagulopathy, encephalopathy, acute kidney injury, acute respiratory distress syndrome, and hypotension due to vasodilation, increased endothelial permeability, and functional adrenal insufficiency. A compensatory antiinflammatory response may follow in which immuneparalysis predisposes the host to further secondary infection. ${ }^{4}$ In the context of this paradigm, sepsis, severe sepsis, and septic shock represent a continuum of increasing disease severity rather than discrete clinical entities with unique pathogeneses. In the 1990s, systemic inflammatory response syndrome (SIRS) was identified as being caused by either infection or trauma and became the early indicator of possible sepsis, prior to that, a diagnosis of sepsis often required evidence of positive blood cultures or confirmation of a documented infection with a microorganism, and in many circumstances also required the presence of shock or hypotension. ${ }^{5}$ Sepsis begins within a nidus of infection with the microbial load increasing over time if untreated, overlying this microbial load is the toxic burden (exotoxins, structural toxins, etc.), the inflammatory response, and the cellular dysfunction/injury driven by inflammatory endogenous mediators which if left unchecked over a finite period of time leads to irreversible organ injury and death. The transition from reversible to irreversible shock will vary depending on the individual genetic predisposition and characteristics of the patient but delayed and/or ineffective antimicrobial therapy permits microbial replication to continue unchecked, resulting in more time spent above the shock threshold and progression to irreversible shock and death. The importance of antimicrobial therapy has been long accepted and is well established in modern sepsis care. ${ }^{6}$ If present study objective in septic shock is the rapid reduction of total microbial load before progression to irreversible shock, then empiric antimicrobial therapy must assume a position of coprimacy in the initial resuscitation with an eye toward optimizing selection, delivery, and cidality at the first dose. Keeping these facts in consideration this study was aimed to test the sensitivity of SIRS criteria in detecting sepsis and to study the outcome of early aggressive empirical antimicrobial therapy in the SIRS positive septicemia.

\section{METHODS}

This is a prospective observational study on the patients of sepsis, attending medicine department (OPD, IPD and medicine ICU) of HAHC hospital which is attached to Hamdard institute of medical sciences and research, Jamia Hamdard, New Delhi. The study period was from May2018 to November-2018 (6 months). Patients attending medicine OPD, admitted patients or who stayed in ICU were screened for features of systemic inflammatory response syndrome (SIRS), sepsis and severe sepsis as per the ACCP/SCCM criteria. ${ }^{7}$. SIRS was considered to be present when patients had two or more of the following clinical findings; (1) body temperature higher than $38^{\circ} \mathrm{C}$ or lower than $36^{\circ} \mathrm{C}(2)$ heart rate higher than 90beats /minutes (3) hyperventilation evidenced by respiratory rate higher than 20/minute or $\mathrm{PO}_{2}$ lower than $36 \mathrm{mmHg}$ (4) white blood cell count higher than 12,000 cells/ $\mu$ l or lower than $4000 / \mu 1 .{ }^{8}$. Sepsis was defined by the presence of both SIRS score $\geq 2$ and infection. Presence of one of these six criteria is needed to confirm that the episode was due to infection, (i) polymorphonuclear cells in normally sterile site (ii) culture of pathogenic organism from normally sterile site (iii) chest X-ray changes consistent with pneumonia (iv) focus of infection identified visually (v) underlying disease or condition known to be associated with infection (e.g. ascending cholangitis); and (vi) any other reason had to be stated. Severe sepsis referred to the presence of sepsis with at least one criterion for organ dysfunction. ${ }^{7}$ The criteria for organ dysfunction were adapted from those used in the PROWESS study and the source of infection was defined by adopting criteria from ANZICS study. ${ }^{9}$ Variables that were recorded on admission included age, sex, primary diagnosis, chronic comorbidities, clinical and laboratory data. Additional data collected included infection site and infection source (outside or in hospital). Body fluid samples as indicated (blood, urine, sputum, pus from any site, pleural, and peritoneal fluids) were sent for microbial assessment on the first day of presumed sepsis and during hospital stay if clinically indicated (new onset fever, new chest infiltrates, and hypotension) for identifying causative pathogens. Details of the drugs (empiric antimicrobials) prescribed including the antibiotics (name, dose, frequency, and route of administration) were recorded and patients were followed for outcome.

\section{Inclusion criteria}

- Patients fulfilling 2 or more out of 4 SIRS criteria.

- Patients of either sex of $\geq 18$ years of age and

- Patients able to give written informed consent.

\section{Exclusion criteria}

- Patients not fulfilling SIRS criteria.

- Patients of $<18$ years of age.

- Patients who were discharged within 24 hours without developing sepsis or complications.

- Very sick patients.

- Pregnant and lactating woman

\section{Statistical analysis}

Data were analyzed by using SPSS 23 version for descriptive statistics, frequency percentage and presented in the tabular form.

\section{RESULTS}

A total 105 patients fulfilling SIRS criteria of sepsis were included in the study and followed till the final outcome (full recovery or death), in that male $(71.42 \%$ ) outnumbered female (28.57\%), Majority (45.71\%). of the patients were from elderly age group of $>60$ years (Table 1). 
Table 1: Age and gender distribution of the study patients.

\begin{tabular}{|llll|}
\hline $\begin{array}{l}\text { Age } \\
\text { (year) }\end{array}$ & Male & Female & $\begin{array}{l}\text { Total no. } \\
(\%)\end{array}$ \\
\hline$<20$ & 00 & 00 & 00 \\
\hline $20-40$ & 16 & 10 & $26(24.76 \%)$ \\
\hline $41-60$ & 27 & 04 & $31(29.52 \%)$ \\
\hline$>60$ & 32 & 16 & $48(45.71 \%)$ \\
\hline Total & $75(71.42 \%)$ & $30(28.57 \%)$ & 105 \\
\hline
\end{tabular}

\section{Sensitivity of SIRS criteria for diagnosing sepsis}

Out of 105 patients with SIRS score $\geq 2$ included in the study, further evaluation confirmed that $82.85 \% \quad(n=87)$ $(\mathrm{p}=<0.05)$ were having different grades of septicemia ranging from sepsis $(59.04 \%)$ to severe sepsis in $18.39 \%$ and septic shock $10.34 \%$ (Table 2).

\section{Primary source of infection}

on the basis of suspected or confirmed report the most frequent primary source of infection was respiratory tract
(44.76\%), followed by urinary tract infection (29.52\%), and skin (mostly in bed ridden patients) $(24.13 \%$ ) (Table 3). Microbiological documentation was available only in $48(55.17 \%)$ cases which sowed that the majority of the infections $(66.66 \%)$ were caused by Gram-negative organisms e.g. Klebsiella species, E. coli and Pseudomonas.

\section{Table 2: Patients with SIRS $\geq 2$ with or} without septicemia.

\begin{tabular}{|lll|}
\hline Frequency of sepsis & Number & $\%$ \\
\hline SIRS $\geq 2$ (no signs of infection) & 18 & 17.14 \\
\hline $\begin{array}{l}\text { Sepsis (SIRS score } \geq 2+ \\
\text { confirmed or suspected infection) }\end{array}$ & 62 & 59.04 \\
\hline $\begin{array}{l}\text { Severe sepsis (sepsis + signs of } \\
\text { end-organ damage, hypotension }\end{array}$ & 16 & 15.23 \\
$\begin{array}{l}\text { SBP <90, Lactate }>\text { 4mmol) } \\
\text { Septic shock (severe sepsis with } \\
\text { persistent: signs of end-organ } \\
\text { damage, hypotension (SBP <90) } \\
\text { and lactate }>4 \text { mmol }\end{array}$ & 09 & 08.57 \\
\hline Total & 105 & 100 \\
\hline
\end{tabular}

Table 3: Primary source of infection and empirical antimicrobial therapy administered.

\begin{tabular}{|c|c|c|c|}
\hline Primary source of infection & No. & Antibiotic prescribed (empirical therapy) & No. \\
\hline \multirow{7}{*}{ Respiratory system } & \multirow{7}{*}{$47(44.76 \%)$} & Piperacillin + tazobactum + amikacin & 15 \\
\hline & & Piperacillin + tazobactum + clindamycin & 11 \\
\hline & & Meropenem + levofloxacin & 07 \\
\hline & & Meropenem + amoxicillin and clavulanic acid & 05 \\
\hline & & Meropenem + polymyxin-B & 04 \\
\hline & & Piperacillin + tazobactum + amikacin + moxifloxacin & 02 \\
\hline & & $\begin{array}{l}\text { Piperacillin + tazobactum + amikacin }+ \text { clindamycin } \\
\text { tazobactum }+ \text { teicoplanin }\end{array}$ & $\begin{array}{l}02 \\
01\end{array}$ \\
\hline \multirow{4}{*}{ Urinary tract infection } & \multirow{4}{*}{$31(29.52 \%)$} & Piperacillin + tazobactum + amikacin & 18 \\
\hline & & ceftriaxone + levofloxacin & 06 \\
\hline & & $\begin{array}{l}\text { Cefaperazone with sulbactam }+ \text { levofloxacin }+ \\
\text { clindamycin }\end{array}$ & 05 \\
\hline & & Piperacillin + tazobactum + linezolid & 02 \\
\hline \multirow{3}{*}{$\begin{array}{l}\text { Skin (mainly due to bed sore } \\
\text { in bed ridden patients) }\end{array}$} & \multirow{3}{*}{$15(14.28 \%)$} & Meropenem + amikacin + tigecycline & 08 \\
\hline & & Piperacillin + tazobactum + amikacin & 05 \\
\hline & & Meropenem + clindamycin & 02 \\
\hline Abdominal and pelvis & $08(07.19 \%)$ & Ceftriaxone + amikacin + metronidazole & 08 \\
\hline Blood stream & $04(3.80 \%)$ & Piperacillin + tazobactum + clarithromycin + meropenem & 04 \\
\hline
\end{tabular}

\section{Empirical antimicrobials use}

Most frequently prescribed empirical antimicrobial agents were Piperacillin with tazobactum in combination with amikacin (40\%). For respiratory and urinary source of infection a combination of piperacillin with tazobactum in combination of amikacin was the most frequently prescribed antimicrobial $33.5 \%$ and $58.06 \%$, whereas for dermal source of infection a combination of meropenem, amikacin and tigecycline was most frequently prescribed $(56 \%)$, and for abdominal source of infection a combination ceftriaxone, amikacin and metronidazole used (Table 3).

\section{Number of antimicrobials prescribed per prescription}


Majority of patients 74 (70.47\%) needed a combination of two antimicrobials in empirical therapy.

Table 4: Number of antimicrobial prescribed per prescription based on source of infection.

\begin{tabular}{|llll|}
\hline $\begin{array}{l}\text { Primary } \\
\text { source of } \\
\text { infection }\end{array}$ & $\begin{array}{l}\text { Number of antimicrobials prescribed } \\
\text { patients }\end{array}$ & $\begin{array}{l}\text { Two } \\
\text { antimicrobials }\end{array}$ & $\begin{array}{l}\text { Triple } \\
\text { antimicrobials }\end{array}$ \\
\hline $\begin{array}{l}\text { Respiratory } \\
\text { system }\end{array}$ & 47 & $43(91.48 \%)$ & $04(8.51 \%)$ \\
\hline $\begin{array}{l}\text { Urinary } \\
\text { system }\end{array}$ & 31 & $25(80.64 \%)$ & $06(22.58 \%)$ \\
\hline Skin & 15 & $07(46.66 \%)$ & $08(53.33 \%)$ \\
\hline $\begin{array}{l}\text { Abdominal } \\
\text { and pelvis }\end{array}$ & 08 & 00 & $08(100 \%)$ \\
\hline $\begin{array}{l}\text { Blood } \\
\text { stream }\end{array}$ & 04 & 00 & $04(100 \%)$ \\
\hline Total & 105 & $74(70.47 \%)$ & $31(29.52 \%)$ \\
\hline
\end{tabular}

Majority of septicemia due to respiratory and urinary tract infection were treated by using a combination of two antimicrobials, $91.48 \%$ and $80.64 \%$ respectively whereas septicemia caused by abdomen and blood source of infection needed a combination of three drugs (Table 4).

\section{Type of antimicrobials prescribed}

Almost all the prescription contained one or other beta lactam antibiotic among them piperacillin and meropenem (56.19\% and $28.57 \%$ respectively), were most frequently prescribed followed by aminoglycoside (e.g. amikacin) (47.61\%), fluoroquinolones and clindamycin ((19.04\% each) (Table 5).

\section{Duration of antimicrobial use and therapeutic outcome}

Of the total 105 patients with SIRS score $\geq 2$, the patients without any signs of infection recovered after receiving antimicrobial for $<3$ days $(72.22 \%)$, the majority of patients with suspected or confirmed sepsis received antimicrobial for 3-7 days (59.67\%), and patients with severe sepsis needed antimicrobial for 8-15 days or even more than 15 days $(68.75 \%)$, whereas most of patient with septic shock either needed prolonged antimicrobial $(33.33 \%)$ or died during treatment $(66.66 \%)$. Overall mortality rate was $7.61 \%$ (Table 6).

Table 5: Classes of antibacterial prescribed.

\begin{tabular}{|lll|}
\hline Antimicrobial class & Name of antimicrobial & No. of drugs $(\%)$ \\
\hline Beta lactam antimicrobials & & $59(56.19 \%)$ \\
\hline $\begin{array}{l}\text { Extended spectrum penicillin (antipseudomonal } \\
\text { penicillin) with beta lactamase inhibitor }\end{array}$ & Piperacillin + tazobactum & $5(4.76 \%)$ \\
\hline Extended spectrum penicillin with beta lactamase inhibitor & Amoxicillin + clavulanic acid & $30(28.57 \%)$ \\
\hline Carbapenem & Meropenem & $08(7.61 \%)$ \\
\hline Cephalosporin (third generation) & Ceftriaxone & $05(4.76 \%)$ \\
\cline { 2 - 3 } & Cefaperazone + sulbactam & $50(47.61 \%)$ \\
\hline Aminoglycosides & Amicacin & $18(17.14 \%)$ \\
\hline Fluoroquinolones & Levofloxacin & $02(1.90 \%)$ \\
\cline { 2 - 3 } & Moxifloxacin & $20(19.04 \%)$ \\
\hline Lincosamide & Clindamycin & $08(7.61 \%)$ \\
\hline Tetracycline & Tigecycline & $08(7.61 \%)$ \\
\hline Nitroimidazole & Metronidazole & $04(3.80 \%)$ \\
\hline Polypeptide antibiotic & Polymyxin-B & $02(1.90 \%)$ \\
\hline Oxazolidinone & Linezolid & 5 \\
\hline
\end{tabular}

Table 6: Duration of antimicrobial use and therapeutic outcome.

\begin{tabular}{|c|c|c|c|c|c|c|}
\hline & $\begin{array}{l}\text { No. of } \\
\text { patient }\end{array}$ & $<3$ days & 3-7 days & 8-15 days & $>$ 15days & $\begin{array}{l}\text { In-hospital } \\
\text { mortality }\end{array}$ \\
\hline $\begin{array}{l}\text { SIRS score } \geq 2 \\
\text { without any signs of } \\
\text { sepsis }\end{array}$ & 18 & $13(72.22 \%)$ & $05(27.77 \%)$ & 00 & 00 & 00 \\
\hline Sepsis & 62 & 00 & $37(59.67 \%)$ & $25(23.80 \%)$ & 00 & 00 \\
\hline Severe sepsis & 16 & 00 & $03(18.75 \%)$ & $08(50.00 \%)$ & $03(18.75 \%)$ & $02(12.50 \%)$ \\
\hline Septic shock & 09 & 00 & 00 & 00 & $03(33.33 \%)$ & $06(66.66 \%)$ \\
\hline Total & 105 & $13(12.38 \%)$ & $45(42.85 \%)$ & $33(31.42 \%)$ & $06(05.70 \%)$ & $08(7.61 \%)$ \\
\hline
\end{tabular}




\section{DISCUSSION}

The primary purpose of our study was to document the incidence and outcome of sepsis occurring in adult patients, as Sepsis is a major cause of morbidity and mortality and the second leading cause of death worldwide. ${ }^{10}$ While the incidence of severe sepsis and septic shock continues to rise annually due in part to increased awareness and recognition, aggressive advances in medical care, and an aging population with many chronic medical comorbidities, in-hospital mortality has declined significantly over the past decade. ${ }^{11,12}$ Large number of septic patient surviving their illness, demonstrate an increased mortality rate over the next 8 years compared with age-matched non-septic critical care survivors. ${ }^{13}$ The concept of systemic inflammatory response syndrome (SIRS) to describe the complex pathophysiologic response to an insult such as infection, trauma, burns, pancreatitis, or a variety of other injuries came from a 1991 consensus conference charged with the task of developing an easy-toapply set of clinical parameters to aid in the early identification of potential candidates to enter into clinical trials to evaluate new treatments for sepsis. The American College of Chest Physicians and Society of Critical Care Medicine Consensus Conference proposed a broad framework to define systemic inflammatory response syndrome (SIRS), sepsis, and severe sepsis. ${ }^{14}$ This syndrome was envisioned as a continuum of worsening inflammation, starting with SIRS, and evolving from sepsis to severe sepsis and septic shock. Although the use of the SIRS criteria has been questioned, and a recent consensus conference has suggested a new approach, for the past decade these criteria have been the accepted approach to diagnose severe sepsis and to select patients for sepsis trials. ${ }^{8,15-17}$ In the present study we used to screen the patients of sepsis based on SIRS criteria and found that SIRS criteria is $82.85 \%$ sensitive in detecting sepsis cases, this indicate that prospective use of SIRS criteria is a valuable guide for early detection and treatment of sepsis which is crucial to halt the progress of disease. In present study males patients predominates $(71.42 \%)$ over female in number $(28.57 \%)$, this complies with the earlier studies. ${ }^{18,19}$ In accordance to the other investigators the most common source of primary infection was respiratory tract and most frequently prescribed antimicrobial was of piperacillin an extended spectrum penicillin effective against pseudomonas with tazobactum a beta lactamase $(56.19 \%)$ and combining this with amikacin indicates that the primary source of infection in septicemia is a mixture of gram positive and gram negative bacteria with predominance of gram positive, this is with some contrast to earlier study. ${ }^{20-26}$ Cases, where source of infection was abdomen antimicrobial covering anaerobes (e.g. metronidazole) was also added, this was in agreement with the other investigators that the initial drugs should have activity against typical gram-positive and gram-negative causative micro-organisms and anaerobic coverage should be provided for intra-abdominal infections or others where anaerobes are significant pathogens. ${ }^{27}$ Delivery of appropriate empiric antimicrobial therapy is critical in early achievement of therapeutic drug levels because initiation of inappropriate therapy is functionally equivalent to starting no antimicrobial at all. Inappropriate antimicrobial therapy for blood stream infections has historically been reported in anywhere from 15 to $30 \%$ of patients admitted to the ICU and is associated with increased hospital mortality, particularly in the setting of severe sepsis and septic shock. ${ }^{28-31}$ As reported by Buckman et al, early administration of broad-spectrum antimicrobial is one of the most important, treatment for patients with sepsis or septic shock, the risk of progression from severe sepsis to septic shock increases $8 \%$ for each hour before antibiotics are started..$^{32}$ Selection of antimicrobial agents is based on a combination of patient factors, predicted infecting organism(s), and local microbial resistance patterns. The duration and type of antimicrobial therapy was determined by the infecting microorganism, site of primary source of infection and Patient risk factors including chronic comorbid diseases (e.g., diabetes mellitus, chronic kidney disease), and immune status. In the present study most of the patients with no evidence of bacterial infection needed antimicrobial therapy only for 2-3days $(72.22 \%)$, whereas patients with Severe sepsis required more than 10days antimicrobial treatment with overall $12.5 \%$ mortality rate and $66.66 \%(\mathrm{p}=<0.005)$ mortality in patients who developed septic shock, the cause of mortality in these patients where organ failure as majority of these were elderly and bedridden (i.e. immune compromised) and primary source of infection was respiratory tract (e.g. pneumonia), this is in accordance to the earlier reports. ${ }^{33-37}$ There is evidence that infection can be persistent in sepsis and septic shock. In a study of 235 patients admitted to a surgical intensive care unit for sepsis or septic shock, more than three quarters of patients were found at autopsy to have a persistent focus of infection. ${ }^{38}$ Mechanisms underlying increased long-term mortality and morbidity remain unclear. Unresolved immune response during recovery may worsen long-term outcomes. For example, higher circulating levels of inflammatory and coagulation markers were observed at hospital discharge when patients appeared to have clinically recovered from infection and increased subsequent mortality. ${ }^{39}$

\section{CONCLUSION}

Despite significant advances in critical care mortality and morbidity in severe sepsis and septic shock remain high this may be explained by the fact that in sepsis bacterial infection triggers the innate immune response, setting in motion a cascade of pro-inflammatory and antiinflammatory cytokines leading to what we recognize as the systemic inflammatory response syndrome (SIRS). It has been thought that this self-propagating cascade drives the progression to severe sepsis and septic shock with increasing degrees of cellular injury and end-organ dysfunction, irrespective of the initial infectious trigger and its rapid elimination with antimicrobial therapy. Therefor early initiation of empirical antimicrobial agent is crucial atleast in patients with impaired cardiovascular function 
who may succumb to septic shock at a lower threshold. The transition from reversible to irreversible shock may also depends on the individual genetic predisposition and characteristics of the patient. The microbiologic paradigm suggests that rapid elimination of the underlying focus of infection with effective antimicrobial therapy can quickly terminate the downstream manifestations of severe sepsis and septic shock. Further study is needed to see the role of immunomodulator in the patient of septicemia (atleast in the patients with severe sepsis and septic shock) for their role in recovery of these patients and prevention of longterm complications.

\section{Funding: No funding sources}

Conflict of interest: None declared

Ethical approval: The study was approved by the Institutional Ethics Committee

\section{REFERENCES}

1. Kumar A, Ellis P, Arabi Y, Roberts D, Light B, Parrillo JE, et al. Initiation of inappropriate antimicrobial therapy results in a five-fold reduction of survival in human septic shock. Chest. 2009; 136:1237-48.

2. Gogos CA, Drosou E, Bassaris HP, Skoutelis A. Proversus anti-inflammatory cytokine profile in patients with severe sepsis: a marker for prognosis and future therapeutic options. J. Infect. Dis. 2000;181:176-80.

3. Bone RC, Grodzin CJ, Balk RA. Sepsis: a new hypothesis for pathogenesis of the disease process. Chest. 1997;112:235-43.

4. Choileain NN, Redmond HP. The immunological consequences of injury. Surgeon. 2006;4:23-31.

5. Bone RC, Balk RA, Cerra FB, Dellinger RP, Fein AM, Knaus WA, et al. The ACCP/SCCM Consensus Conference Committee. Am Coll Chest Physicians/Society of Critical Care Medicine Definitions for sepsis and organ failure and guidelines for the use of innovative therapies in sepsis. Chest. 1992;101:1644-55.

6. Dellinger RP, Levy MM, Rhodes A, Annane D, Gerlach H, Opal SM, et al. Surviving sepsis campaign: international guidelines for management of severe sepsis and septic shock: 2012. Crit Care Med. 2013;41:580-637.

7. Balk RA. Pathogenesis and management of multiple organ dysfunction or failure in severe sepsis and septic shock. Crit Care Clin. 2000;16:337-52, vii. [PubMed] [CrossRef].

8. Bernard GR, Vincent JL, Laterre PF, LaRosa SP, Dhainaut JF, Lopez-Rodriguez A, et al. Efficacy and safety of recombinant human activated protein $\mathrm{C}$ for severe sepsis. N Engl J Med. 2001;344:699-709.

9. Finfer S, Bellomo R, Lipman J, French C, Dobb G, Myburgh J. Adult-population incidence of severe sepsis in Australian and New Zealand Intensive Care Units. Intensive Care Med. 2004;30:589-96.
10. Linde-Zwirble WT, Angus DC. Severe sepsis epidemiology: Sampling, selection, and society. Crit Care. 2004;8:222-6.

11. Gaieski DF, Edwards JM, Kallan MJ, Carr BG. Benchmarking the incidence and mortality of severe sepsis in the United States. Crit Care Med. 2013;41:1167-74.

12. Walkey AJ, Wiener RS, Lindenauer PK. Utilization patterns and outcomes associated with central venous catheter in septic shock: a population-based study. Crit Care Med. 2013;41:1450-7.

13. Dreiher J, Almog Y, Sprung CL, Codish S, Klein M, Einav S, et al. SEPSIS-ISR Group Temporal trends in patient characteristics and survival of intensive care admissions with sepsis: a multicenter analysis. Crit Care Med. 2012; 40:855-60.

14. Balk RA. Severe sepsis and septic shock. Definitions, epidemiology, and clinical manifestations. Crit Care Clin. 2000;16:179-92. [PubMed] [CrossRef].

15. Vincent JL. Dear SIRS, I'm sorry to say that I don't like you. Crit Care Med. 1997 Feb 1;25(2):372-4.

16. Abraham E, Matthay MA, Dinarello CA, Vincent JL, Cohen J, Opal SM, et al. Consensus conference definitions for sepsis, septic shock, acute lung injury, and acute respiratory distress syndrome: time for a reevaluation. Crit Care Med. 2000 Jan 1;28(1):232-5.

17. Levy MM, Fink MP, Marshall JC, Abraham E, Angus D, Cook D, et al. $2001 \mathrm{sccm} / \mathrm{esicm} / \mathrm{accp} / \mathrm{ats} / \mathrm{sis}$ international sepsis definitions conference. Intensive Care Med. 2003 Apr 1;29(4):530-8.

18. Thomas Z. Study on drug utilization, prescribing pattern of antibiotic in the management of diabetic foot ulcer. IJIPSR 2015;3(8):1037-49.

19. Peter N, Cherian N, Thomas S, George S, Sundresh N. study on prescribing pattern and use of antibiotic in the management of wound infection. Asian J Pharm Clin Res. 2017;10(2):210-3.

20. Brun-Buisson C, Doyon F, Carlet J, Dellamonica P, Gouin F, Lepoutre A, et al. Incidence, risk factors, and outcome of severe sepsis and septic shock in adults: a multicenter prospective study in intensive care units. JAMA. 1995 Sep 27;274(12):968-74.

21. Sands KE, Bates DW, Lanken PN, Graman PS, Hibberd PL, Kahn KL, et al. Epidemiology of sepsis syndrome in 8 academic medical centers. JAMA. 1997 Jul 16;278(3):234-40.

22. Martin GS, Mannino DM, Eaton S, Moss M. The epidemiology of sepsis in the United States from 1979 through 2000. N Engl J Med. 2003;348:1546-54.

23. Finfer S, Bellomo R, Lipman J, French C, Dobb G, Myburgh J. Adult-population incidence of severe sepsis in Australian and New Zealand intensive care units. Intensive Care Med. 2004;30:589-96.

24. Brun-Buisson C, Doyon F, Carlet J. Bacteremia and severe sepsis in adults: a multicenter prospective survey in ICUs and wards of 24 hospitals. French Bacteremia-Sepsis Study Group. Am J Resp Crit Care Med. 1996 Sep;154(3):617-24.

25. Vincent JL, Sakr Y, Sprung CL, Ranieri VM, Reinhart $\mathrm{K}$, Gerlach H, et al. Sepsis Occurrence in Acutely Ill 
Patients Investigators Sepsis in European intensive care units: results of the SOAP study. Crit Care Med. 2006;34:344-53.

26. Friedman G, Silva E, Vincent JL. Has the mortality of septic shock changed with time. Crit Care Med. 1998;26:2078-86.

27. Ibrahim EH, Sherman G, Ward S, Fraser VJ, Kollef $\mathrm{MH}$. The influence of inadequate antimicrobial treatment of bloodstream infections on patient outcomes in the ICU setting. Chest. 2000 Jul $1 ; 118(1): 146-55$.

28. Valles J, Rello J, Ochagavía A, Garnacho J, Alcalá MA. Community-acquired bloodstream infection in critically ill adult patients: impact of shock and inappropriate antibiotic therapy on survival. Chest. 2003 May 1;123(5):1615-24.

29. Micek ST, Welch EC, Khan J, Pervez M, Doherty JA, Reichley RM, et al. Empiric combination antibiotic therapy is associated with improved outcome against sepsis due to Gram-negative bacteria: a retrospective analysis. Antimicrob Chemotherapy. 2010 May 1;54(5):1742-8.

30. Paul M, Shani V, Muchtar E, Kariv G, Robenshtok E, Leibovici L. Systematic review and meta-analysis of the efficacy of appropriate empiric antibiotic therapy for sepsis. Antimicrob Agents Chemotherapy. 2010 Nov 1;54(11):4851-63.

31. Liang SY, Kumar A. Empiric antimicrobial therapy in severe sepsis and septic shock: optimizing pathogen clearance. Curr Infect Dis Reports. 2015 Jul $1 ; 17(7): 36$

32. Buckman SA, Turnbull IR, Mazuski JE. Empiric antibiotics for sepsis. Surg Infect (Larchmt). 2018 Feb/Mar; 19(2):147-154.

33. Clinical Excellence Commission. Adult Antibiotic Guideline for Severe Sepsis and Septic Shock. 2016(3):4-9. Available at: http://www.cec.health.nsw.gov.au/_data/assets/pdf_ file/0005/299417/adult-antibiotic-guideline-severesepsis-septic-shock-sept2016.pdf.

34. Esper AM, Moss M, Lewis CA, Nisbet R, Mannino DM, Martin GS. The role of infection and comorbidity: Factors that influence disparities in sepsis. Crit Care Med. 2006;34:2576-82.

35. Moss M. Epidemiology of sepsis: race, sex, and chronic alcohol abuse. Clin Infect Dis. 2005; 41(Suppl 7):S490-7.

36. Angus DC, Linde-Zwirble WT, Lidicker J, Clermont G, Carcillo J, Pinsky MR. Epidemiology of severe sepsis in the United States: analysis of incidence, outcome, and associated costs of care. Crit Care Med. 2001;29:1303-10.

37. Mayr FB, Yende S, Linde-Zwirble WT, Peck-Palmer OM, Barnato AE, Weissfeld LA, Angus DC. Infection rate and acute organ dysfunction risk as explanations for racial differences in severe sepsis. JAMA. 2010;303:2495-503.

38. Torgersen C, Moser P, Luckner G, Mayr V, Jochberger S, Hasibeder WR, et al. Macroscopic postmortem findings in 235 surgical intensive care patients with sepsis. Anesth Analg. 2009;108:1841-7.

39. Yende S, D’Angelo G, Kellum JA, Weissfeld L, Fine J, Welch RD, Kong L, Carter M, Angus DC, GenIMS Investigators Inflammatory markers at hospital discharge predict subsequent mortality after pneumonia and sepsis. Am J Respir Crit Care Med. 2008; 177:1242-7.

Cite this article as: Habib A, Ahmad R. Antimicrobial utilization pattern in Systemic Inflammatory Response Syndrome positive septicemia: a prospective study in an apex hospital in South Delhi. Int J Basic Clin Pharmacol 2019;8:55763. 